\title{
Persuasive antimicrobial stewardship intervention in the context of a KPC outbreak: a controlled interrupted time series analysis
}

Nuno Rocha Pereira ( $\square$ nunopereira85@gmail.com )

Hospital São João https://orcid.org/0000-0003-3512-0777

Paulo Figueiredo Dias

Centro Hospitalar Universitario de Sao Joao

\section{Sofia Correia}

Universidade do Porto Instituto de Saude Publica

\section{Shirin Shahriari}

Universidade do Porto Instituto de Saude Publica

\section{João Neves}

Centro Hospitalar Universitario de Sao Joao

\section{José Teixeira}

Centro Hospitalar Universitario de Sao Joao

José Artur Paiva

Centro Hospitalar Universitario de Sao Joao

\section{Carlos Lima Alves}

Centro Hospitalar Universitario de Sao Joao

\section{Ana Azevedo}

Centro Hospitalar Universitario de Sao Joao

\section{Research}

Keywords: Antimicrobial stewardship, Interrupted time series, Prospective audit and feedback, Antibiotic resistance

Posted Date: December 20th, 2019

DOI: https://doi.org/10.21203/rs.2.19351/v1

License: (c) (1) This work is licensed under a Creative Commons Attribution 4.0 International License. Read Full License 


\section{Abstract}

Introduction: Antimicrobial resistance is a major public health threat. Antimicrobial stewardship (AMS) is one of the key strategies to overcome resistance, but robust evidence on the effect of specific interventions is lacking. We report an interrupted time series (ITS) analysis of a persuasive AMS intervention implemented during a KPC producing Klebsiella pneumoniae outbreak.

Methods: A controlled ITS for carbapenem consumption, total antibiotic consumption and antibiotic-free days, between January 2012 and May 2018 was performed, using segmented regression analysis. The AMS intervention was implemented in the Vascular Surgery ward starting on April 2016 in the context of a KPC outbreak. The General Surgery ward was taken as a control group. Data were aggregated by month for both wards, including 51 pre-intervention and 26 intervention points.

Results: The AMS intervention produced a level change in carbapenem consumption of -9.92 DDDs/100 patient-days accompanied by a reduction of total antibiotic consumption and an increase of $4 \%$ in antibiotic-free days in Vascular Surgery ward. These differences were not apparent in the control group. No differences in mortality or readmission rates between pre-intervention and intervention periods were noticed in any of the groups.

Conclusion: Persuasive AMS interventions on top of previously implemented restrictive interventions can reduce carbapenem consumption and increase antibiotic-free days. Starting persuasive AMS interventions in an outbreak setting does not compromise the sustainability of the intervention.

\section{Introduction}

Antimicrobial resistance is a major threat to public health worldwide[1, 2] and there is a global call for action to preserve antibiotics for future generations $[3,4]$. Antimicrobials use is deemed inappropriate in at least half of cases and it is well established that antimicrobial use contributes to the development and spread of resistance[5].

In Portugal carbapenem resistance is concerning [6] with several outbreaks of carbapenemase producing Enterobacteriaceae registered over the last years and growing proportion of carbapenem resistance noticed in epidemiological surveillance. This kind of bacteria poses major challenges to medical community because of the very few treatment options.

Antimicrobial stewardship (AMS) is one of the key strategies to overcome resistance and implementation of such programs is recommended across the globe.[7] These programs aim to improve patient outcomes and safety by improving antimicrobials use and also to reduce emergence of antimicrobial resistance.[8-10] Persuasive and restrictive interventions may be used and both have shown efficacy in reducing antimicrobial consumption[11,12], duration of therapy, length of stay and also in increasing compliance with guidelines.[11, 12] Some evidence, although less robust, also exists for the role of such strategies in reducing antimicrobial resistance.[12] However, robust evidence supporting different kinds of 
AMS interventions is still incomplete.[13] To fulfil this gap, in a pragmatic and realistic approach, the use of interrupted time series (ITS) analysis can be useful to evaluate complex interventions used in AMS programs.[3, 9, 14]

We conducted a controlled ITS to assess the impact of a set of persuasive AMS strategies implemented in a Vascular Surgery ward in the context of a KPC outbreak.

\section{Methods}

\subsection{Setting and design}

This study was conducted in Centro Hospitalar Universitário de São João, a 1100-bed tertiary care public teaching hospital in Porto, Portugal. A set of restrictive AMS strategies including formulary restriction, preauthorization of restricted antimicrobials and automatic stop-orders have been implemented and sustained in all wards for several years. In 2014, following the national legislation, the Infection and Antimicrobial Resistance Control and Prevention Unit (UPCIRA) was created and became responsible for both infection prevention and control and AMS program. Since then, UPCIRA has implemented several persuasive AMS interventions, particularly prospective audit and feedback, in various wards. In April 2016, an outbreak of carbapenemase producing Klebsiella pneumoniae was identified in the Vascular Surgery ward. The identification of this outbreak prompted UPCIRA to act and alongside with infection control and prevention measures, an analysis of the factors that might have contributed to the occurrence of the outbreak identified excessive use of antibiotics and a high proportion of patients under carbapenem therapy; also, there were no local guidelines for treatment of diabetic foot infections, one of the most common causes of admission to Vascular Surgery ward. Prospective audit and feedback of antimicrobial prescription and production of a local guideline ensued, and both were fully implemented by the end of May 2016.

We designed a controlled ITS of the period between January 2012 and May 2018 to assess the effect of persuasive AMS strategies on the following endpoints: carbapenems consumption, total antibiotic consumption and proportion of antibiotic-free days.

The period between January 2012 and March 2016 was considered as the pre-intervention period and the period between April 2016 and May 2018 as the intervention period (Fig. 1).

\subsection{Intervention}

Two different strategies were part of the persuasive AMS intervention: local guideline for diabetic foot infection and prospective audit and feedback on antibiotic prescriptions. The local guideline was produced by a multidisciplinary team including infectious diseases physicians, internal medicine and intensive care physicians, vascular surgeons, endocrinologists, microbiologists, pharmacists and AMS team members. The final version of the guideline was available in May 2016 and was then presented in a lecture to all physicians working in the Vascular Surgery ward. It was also released in the hospital intranet 
where it became available to all hospital staff. Prospective audit and feedback intervention included the review of all first prescriptions of restricted antimicrobials, all prescriptions of restricted antimicrobials lasting for more than 96 hours with the intention of changing to directed therapy and all prescriptions of antimicrobials longer than eight days. The review was performed weekly by two infectious diseases physicians that were part of the AMS team and was based on the information available in the electronic medical record. The feedback was given in a weekly face-to-face meeting with the prescribing physicians or the physician in charge of each patient. After feedback was given, a clinical discussion between AMS team and prescribing physicians ensued in order to reach a common agreed treatment strategy. The whole-hospital restrictive interventions described above were maintained unchanged during the intervention period.

The control ward, in the General Surgery department, was under the same restrictive AMS interventions described above for the whole hospital but had no defined specific AMS program.

\subsection{Data collection}

Ward-level data including number of admissions, type of admission (elective vs. urgent), patients' sex and age, length of stay, 30-day readmission and in-hospital mortality were gathered through an in-house business intelligence platform described elsewhere.[15] Inpatient data on all pharmacy-dispensed antibiotics included in the Anatomical Therapeutical Chemical (ATC) group J01 were expressed as defined daily doses (DDDs)/100 patient-days according to the World Health Organization-ATC/DDD index 2013.[16] Using the antibiotics' administration registries, the number of days with no antibiotic was obtained by subtracting the number of days with one or more antibiotic administrations from the number of hospitalization days. The indicator was expressed as a proportion of the entire length of stay. Data were aggregated by month for both wards.

\subsection{Statistical analysis}

Ward characteristics were described as absolute numbers (number of admissions), proportions or means (length of stay). Monthly averages for the pre- and post-intervention periods were compared for each group using T-test, Wilcoxon rank sum test and $\chi 2$ test, as appropriate. Statistical significance was assumed for $\mathrm{p}<0.05$ (two tailed tests).

Carbapenem consumption, total antibiotic consumption and antibiotic free days were analysed separately for Vascular Surgery ward and for the control ward by performing segmented regression analysis of interrupted time series.[3]

We predefined two models to test a) change in the level of each outcome (model 1) and b) change in the level of the outcome and in the slope (model 2, velocity). Models' equations are described in the supplementary file S1. Briefly, outcomes' predictions considered the baseline value of the outcome (

0 ), the underlying pre-intervention trend (

${ }_{1}$, using time as the predictor) and the change in the outcome level after the intervention ( 
2, using a dummy variable defining the intervention). The change in the slope after the intervention (

3), was estimated in model 2 including an interaction term between time and the dummy variable defining the intervention. When no significant change in slope was identified we used model 1 (level change model) to calculate the coefficients. The assumptions of normality, homoscedasticity, and linearity were assessed using the Q-Q plot of residuals, plot of residuals against predicted values and plots of residuals against each variable in the regression model.

The data were analysed with STATA version 14.0 and R software version 3.2.2.

\section{Results}

We included in the ITS analysis 51 points (months) before the intervention and 26 points (months) of intervention.

\subsection{Ward and patient characteristics}

Table 1 summarizes the ward and patient characteristics in both wards in pre-intervention and intervention periods. In the Vascular Surgery ward patients were more commonly males while in control ward there was a predominance of females and this distribution was mantained in pre-intervention and intervention periods. 
Table 1

- General characteristics in Vascular Surgery ward and control group in pre-intervention and intervention periods.

\begin{tabular}{|c|c|c|c|c|c|c|}
\hline & \multicolumn{3}{|c|}{ Vascular Surgery } & \multicolumn{3}{|c|}{ General Surgery } \\
\hline & $\begin{array}{l}\text { Pre- } \\
\text { intervention }\end{array}$ & Intervention & $\begin{array}{l}\mathrm{p}- \\
\text { value }\end{array}$ & $\begin{array}{l}\text { Pre- } \\
\text { intervention }\end{array}$ & Intervention & $\begin{array}{l}\mathrm{p}- \\
\text { value }\end{array}$ \\
\hline \multicolumn{7}{|l|}{$\begin{array}{l}\text { Per month: mean } \\
\text { (sd) }\end{array}$} \\
\hline Admissions (n) & $129(25)$ & $107(20)$ & $\dot{0} 001$ & $478(43)$ & $472(35)$ & 0.575 \\
\hline $\begin{array}{l}\text { Elective } \\
\text { admissions (\%) }\end{array}$ & $74.7(6.7)$ & $61.4(11.9)$ & $<0.001$ & $67.3(3.7)$ & $64.7(4.9)$ & 0.013 \\
\hline Men (\%) & $52.6(6.2)$ & $57.3(7.8)$ & 0.005 & $44.0(2.6)$ & $42.5(2.4)$ & 0.013 \\
\hline \multicolumn{7}{|l|}{ Age $(\%)$} \\
\hline$<40$ & $9.5(3.0)$ & $7.2(3.5)$ & 0.004 & $15.4(1.8)$ & $14.6(1.5)$ & 0.057 \\
\hline $40-64$ & $50.9(5.8)$ & $45.2(6.6)$ & $<0.001$ & $46.4(2.4)$ & $46.7(3.0)$ & 0.706 \\
\hline $65-74$ & $20.3(4.0)$ & $25.6(3.8)$ & $<0.001$ & $20.1(1.8)$ & $19.8(2.3)$ & 0.545 \\
\hline$>=75$ & $19.4(5.3)$ & $22.0(6.1)$ & 0.058 & $18.1(2.0)$ & $18.9(1.9)$ & 0.078 \\
\hline $\begin{array}{l}\text { Average Length of } \\
\text { Stay (days) }\end{array}$ & $7.7(1.5)$ & $9.0(1.4)$ & 0.001 & $5.1(0.5)$ & $5.7(0.4)$ & $\begin{array}{l}< \\
0.001\end{array}$ \\
\hline $\begin{array}{l}\text { 30-days } \\
\text { Readmissions (\%) }\end{array}$ & $8.0(2.4)$ & $8.8(2.6)$ & 0.146 & $11.5(1.8)$ & $12.9(1.7)$ & 0.002 \\
\hline $\begin{array}{l}\text { In-hospital death } \\
(\%)\end{array}$ & $1.6(1.3)$ & $2.1(1.4)$ & 0.167 & $1.6(0.6)$ & $2.2(0.6)$ & $\begin{array}{l}<.001 \\
0.001\end{array}$ \\
\hline
\end{tabular}

The average number of monthly admissions decreased in the Vascular Surgery ward when comparing pre-intervention and intervention periods while in the control ward no statistically significant change was apparent. The proportion of elective admissions among all admissions decreased in both wards when comparing the pre-intervention and intervention periods, with a reduction of $13.3 \%$ in the Vascular Surgery ward.

\subsection{Carbapenem consumption}


In the ITS analysis of carbapenem consumption, both wards had a decreasing trend in pre-intervention period (Table 2 and Fig. 2). In Vascular Surgery ward a level change with intervention implementation was noticed with a decrease of -9.94 DDDs $/ 100$ patient-days $(p<0.001)$ (Table 2$)$. In the control ward no significant level change occurred. In both wards, no significant change in slope during the intervention period, compared to the pre-intervention period, occurred (Table 2). 
Table 2

Interrupted time-series regression analysis of antibiotic consumption (carbapenems and all antibiotics) and antibiotic free-days in vascular and general surgery wards.

\begin{tabular}{|c|c|c|c|c|}
\hline & \multicolumn{2}{|l|}{ Vascular Surgery } & \multicolumn{2}{|l|}{ General Surgery } \\
\hline & $\begin{array}{l}\text { Coefficient } \\
(95 \% \mathrm{Cl})\end{array}$ & $\begin{array}{l}\mathrm{p}- \\
\text { value }\end{array}$ & $\begin{array}{l}\text { Coefficient } \\
(95 \% \mathrm{Cl})\end{array}$ & $\begin{array}{l}\mathrm{p}- \\
\text { value }\end{array}$ \\
\hline \multicolumn{5}{|l|}{$\begin{array}{l}\text { Carbapenem consumption } \\
\text { (DDD/100 PD) }\end{array}$} \\
\hline Baseline level & $\begin{array}{l}19.15(17.21 \\
21.08)^{\star}\end{array}$ & & $8.60(7.71 ; 9.50)^{\star}$ & \\
\hline Pre-intervention slope & $\begin{array}{l}-0.12(-0.19 \\
-0.06)^{*}\end{array}$ & $<.001$ & $\begin{array}{l}-0.06(-0.09 \\
-0.03)^{*}\end{array}$ & $<.001$ \\
\hline $\begin{array}{l}\text { Level change (post intervention) } \\
\end{array}$ & $\begin{array}{l}-9.94(-12.91 \\
-6.97)^{\star}\end{array}$ & $<.001$ & $\begin{array}{l}-1.26(-2.63 \\
0.12)^{\star}\end{array}$ & 0.074 \\
\hline Slope post-intervention & $\begin{array}{l}0.14(-0.07 \\
0.35)^{\star \star}\end{array}$ & 0.185 & $\begin{array}{l}0.02(-0.08 \\
0.12)^{\star \star}\end{array}$ & 0.651 \\
\hline \multicolumn{5}{|l|}{$\begin{array}{l}\text { Overall antibiotic consumption } \\
\text { (DDD/100 PD) }\end{array}$} \\
\hline Baseline level & $\begin{array}{l}55.91(51.90 \\
59.92)^{\star \star}\end{array}$ & & $\begin{array}{l}48.15(45.53 \\
50.79)^{\star \star}\end{array}$ & \\
\hline Pre-intervention slope & $\begin{array}{l}0.09(-0.04 \\
0.22)^{\star \star}\end{array}$ & 0.162 & $\begin{array}{l}-0.12(-0.21 \\
-0.04)^{\star \star}\end{array}$ & 0.006 \\
\hline Level change (post intervention) & $\begin{array}{l}48.9(22.7 \\
75.16)^{\star \star}\end{array}$ & $<.001$ & $\begin{array}{l}-23.55(-40.72 \\
-6.37)^{\star \star}\end{array}$ & 0.008 \\
\hline Slope post-intervention & $\begin{array}{l}-0.89(-1.31 \\
-0.47)^{\star \star}\end{array}$ & $<.001$ & $\begin{array}{l}0.46(0.19 \\
0.74)^{\star \star}\end{array}$ & 0.001 \\
\hline \multicolumn{5}{|l|}{ Days without antibiotic (\%) } \\
\hline Baseline level & $\begin{array}{l}40.45(37.80 \\
43.11)^{\star}\end{array}$ & & $\begin{array}{l}54.24(52.84 \\
55.63)^{\star \star}\end{array}$ & \\
\hline Pre-intervention slope & $0.09(0.01 ; 0.18) *$ & 0.034 & $\begin{array}{l}0.14(0.09 \\
0.19)^{\star \star}\end{array}$ & $\dot{0} 001$ \\
\hline $\begin{array}{l}\text { Level change (post intervention) } \\
\end{array}$ & $4.16(0.08 ; 8.25)^{*}$ & 0.046 & $\begin{array}{l}6.85(-2.23 \\
15.94)^{\star \star}\end{array}$ & 0.137 \\
\hline $\begin{array}{l}\text { Slope post-intervention } \\
\text { ) }\end{array}$ & $\begin{array}{l}0.12(-0.16 \\
0.41)^{\star \star}\end{array}$ & 0.869 & $\begin{array}{l}-0.16(-0.31 \\
-0.02)^{\star \star}\end{array}$ & 0.027 \\
\hline \multicolumn{5}{|c|}{$\begin{array}{l}\text { * From model } 1 \text { (testing only level change) because slope post-intervention was not statistically } \\
\text { significant in model } 2 \text {; }\end{array}$} \\
\hline
\end{tabular}




\subsection{Total antibiotic consumption}

In the ITS analysis of total antibiotic consumption, a significant change in slope between pre-intervention and intervention periods was apparent in both wards (Fig. 3). In the Vascular Surgery ward a significant decreasing trend in intervention period was noticed while in the control ward the opposite occurred (Table 2).

\subsection{Antibiotic free-days}

In both wards a positive trend, reflecting an increasing number of antibiotic-free days, was noticed in preintervention period (Fig. 4). After intervention implementation a significant level change $(4 \%, p<0.046)$ was apparent in the Vascular Surgery ward while no difference was noticed in the control ward. During the intervention period, no significant change in slope occurred in Vascular Surgery ward and in the control ward the slope became decreasing (Table 2).

\subsection{Other endpoints}

Mortality and readmission rates were not significantly different in Vascular Surgery ward in preintervention and intervention periods (Table 1). In contrast, in General Surgery ward a stastically significant increase in both endpoints was observed (Table 1). In both wards a significant increase in the average length of stay occurred when comparing pre-intervention and intervention periods (Table 1).

\section{Discussion}

A persuasive AMS intervention, including local guideline production and prospective audit and feedback, led to a significant decrease in carbapenem consumption and overall antibiotic consumption and to an increase in antibiotic-free days in the intervened ward. Both effects were sustained over 2-years duration of the follow-up. Another study performed in our institution, in the Orthpaedics ward, also showed the impact of persuasive AMS interventions (local guideline plus audit and feedback) in antibiotic consumption. [17] Also, several studies in different settings and applying similar persuasive interventions have shown effect in reducing antimicrobial consumption, both globally and for specific antibiotic classes. $[9,18]$ However, our intervention was designed and implemented in a particularly challenging setting, a KPC outbreak. There are reports that AMS interventions effects usually fade with time with few studies reporting results beyond 24 months $[3,13]$ and the ones implemented during outbreak settings seem to be specially difficult to sustain once the outbreak is controlled.[3] Our study shows that this kind of intervention may have sustainable results even if the initial design and implementation occur in an outbreak setting. There are concerns that reduction in consumption of some particular classes of antibiotics can result in unintended increase in other classes with similar deleterious ecological effects, the so called "squeezing the balloon effect". $[13,19,20]$ In our study we also measured total consumption of antimicrobials and observed a significant decrease in the intervened ward with a change in the previous trend. This finding excludes the existence of a "squeezing the balloon effect" in our study. 
Furthermore, the reduction in carbapenem consumption was accompanied by an increase in antibioticfree days in the intervened ward, a finding not replicated in the control ward.

The main aim of AMS programs is to improve patient care and while reductions in antimicrobial use have been associated with better clinical outcomes,[12,13] this should not be assumed without direct evidence.[3] Our intervention had no impact in patient mortality or readmission rates, however better indicators such as infection-related mortality would be useful to show that this intervention is safe. Molina et al [13] showed that a persuasive intervention can even decrease mortality in the long run but the follow-up time of our study is still too short to assess this. There was an increase in length of stay in the intervention period but this increase was noticed in both groups so it can not be attributed to the AMS intervention alone. Also, further patient characteristics needed analysis in order to understand why the length of stay increased. We may speculate that this finding can be related to the significant increase in the percentage of patients admitted non-electively that can have longer and more complicated admissions.

We recognize that our study has some limitations. This is a single centre study which may hamper generalizability; however, it is also true that AMS interventions, as quality improvement initiatives in general, need to be adapted to specific contexts and our study shares evidence on the efficacy of this kind of AMS interventions. We acknowledge that our control group is not perfect because patients' characteristics and ward dimensions are very different, but it allows to attain the objective of analysing if the differences observed are due to the intervention or due to secular trends in the whole institution.[3, 14]. The duration of our study is not long enough to exclude the possible fading of the effect of the AMS intervention but the more than two years of intervention are reassuring. Furthermore, our ITS complies with the EPOC recommendations of recording at least 12 monthly points before and after intervention.[3, 21] Reduction of resistance is one of the major aims of AMS and we did not record data on the evolution of resistance in our study. However, reducing antibiotic consumption can lead to reduced antimicrobial resistance[12] and also, as reported by Geissler et al[22], longer periods of follow-up are needed to see that kind of effects.[2] As stated above, future analyses of other clinical outcomes like infection-related mortality can be of interest. We may speculate that the fact that our AMS intervention was implemented concurrently with infection control and prevention interventions may have potentiated results, but this

seems not be supported by (a) results are sustained over two years and (b) excluding a six-month period after the beginning of the intervention did not impact the level change in carbapenem consumption that we report (sensitivity analysis, data not shown).

\section{Conclusion}

Our ITS study shows that persuasive AMS interventions on top of already implemented restrictive interventions can reduce carbapenem and total antibiotic consumption and increase antibiotic-free days. It also shows that persuasive AMS interventions can be initiated in outbreak settings without compromising the sustainability of the intervention. 


\section{Declarations}

\subsection{Ethics approval and consent to participate}

Not required for this type of work without individual patient data.

\subsection{Consent for publication}

Not applicable

\subsection{Availability of data and material}

The datasets during and/or analysed during the current study available from the corresponding author on reasonable request

\subsection{Funding}

This paper received no specific funding.

\section{$\underline{6.5 \text { Authors' Contributions }}$}

NRP designed, collected the data and wrote the paper.

PF assisted with study design and reviewed the paper.

SC and SS assisted with study design, collected the data and performed the relevant statistical analysis.

JN, JT, JAP, CA and AA all assisted in study design and helped in paper writting.

\section{$\underline{6.6 \text { Acknowledgements }}$}

Not applicable.

\section{$\underline{6.7 \text { Competing Interests }}$}

The authors declare that they have no competing interests.

\section{References}

1. Holmes AH, Moore LSP, Sundsfjord A, Steinbakk M, Regmi S, Karkey A, Guerin PJ, Piddock LJV. Understanding the mechanisms and drivers of antimicrobial resistance. Lancet. 2016;387:176-87. 
https://doi.org/10.1016/S0140-6736(15)00473-0.

2.

Taggart LR, Leung E, Muller MP, Matukas LM, Daneman N. Differential outcome of an antimicrobial stewardship audit and feedback program in two intensive care units: A controlled interrupted time series study. BMC Infect Dis. 2015;15:1-11. https://doi.org/10.1186/s12879-015-1223-2.

3.

de Kraker MEA, Abbas M, Huttner B, Harbarth S, Pullenayegum E, Devereaux PJ, et alt. Good epidemiological practice: a narrative review of appropriate scientific methods to evaluate the impact of antimicrobial stewardship interventions. Clin Microbiol Infect. 2017;11:21. https://doi.org/10.1016/j.cmi.2017.05.019.

4.

Toma M, Davey PG, Marwick CA, Guthrie B. A framework for ensuring a balanced accounting of the impact of antimicrobial stewardship interventions. J Antimicrob Chemother. 2017;72:3223-31. https://doi.org/10.1093/jac/dkx312.

5 .

Tacconelli E. Antimicrobial use: Risk driver of multidrug resistant microorganisms in healthcare settings. Curr Opin Infect Dis. 2009;22:352-8. https://doi.org/10.1097/QC0.0b013e32832d52e0.

6.

ECDC. (2013) European Centre for Disease Prevention and Control. Point prevalence survey of healthcare associated infections and antimicrobial use in European acute care hospitals.

7.

Barlam TF, Cosgrove SE, Abbo LM, Macdougall C, Schuetz AN, Septimus EJ, Srinivasan A, Dellit TH, FalckYtter YT, Fishman NO, Hamilton CW, Jenkins TC, Lipsett PA, Malani PN, May LS, Moran GJ, Neuhauser MM, Newland JG, Ohl CA, Samore MH, Seo SK, Trivedi KK. Executive summary: Implementing an antibiotic stewardship program: Guidelines by the infectious diseases society of America and the society for healthcare epidemiology of America. Clin Infect Dis. 2016;62:1197-202.

https://doi.org/10.1093/cid/ciw217.

8.

Pereira NR, Castro-Sanchez E, Nathwani D. (2017) How can multi-professional education support better stewardship? Infect Dis Rep 9:. https://doi.org/10.4081/idr.2017.6917.

9 .

la Martire G, Robin C, Oubaya N, Lepeule R, Beckerich F, Leclerc M, Barhoumi W, Toma A, Pautas C, Maury S, Akrout W, Cordonnier-Jourdin C, Fihman V, Venditti M, Cordonnier C. De-escalation and discontinuation strategies in high-risk neutropenic patients: an interrupted time series analyses of antimicrobial consumption and impact on outcome. Eur J Clin Microbiol Infect Dis. 2018.

https://doi.org/10.1007/s10096-018-3328-1.

10.

Borde JP, Litterst S, Ruhnke M, Feik R, Hübner J, deWith K, Kaier K, Kern WV. Implementing an intensified antibiotic stewardship programme targeting cephalosporin and fluoroquinolone use in a 200-bed community hospital in Germany. Infection. 2014;43:45-50. https://doi.org/10.1007/s15010-014-0693-2. 
11.

Davey P, Ca M, Cl S, Charani E, Mcneil K, Brown E, Im G, Cr R, Michie S. Interventions to improve antibiotic prescribing practices for hospital inpatients (Review). Cochrane database Syst Rev CD003543. 2017. https://doi.org/10.1002/14651858.CD003543.pub4.www.cochranelibrary.com.

12.

Baur D, Gladstone BP, Burkert F, Carrara E, Foschi F, Döbele S, Tacconelli E. Effect of antibiotic stewardship on the incidence of infection and colonisation with antibiotic-resistant bacteria and Clostridium difficile infection: a systematic review and meta-analysis. Lancet Infect Dis. 2017;17:9901001. https://doi.org/10.1016/S1473-3099(17)30325-0.

13.

Molina J, Peñalva G, Gil-Navarro MV, Praena J, Lepe JA, Pérez-Moreno MA, Ferrándiz C, Aldabó T, Aguilar M, Olbrich P, Jiménez-Mejías ME, Gascón ML, Amaya-Villar R, Neth O, Rodríguez-Hernández MJ, GutiérrezPizarraya A, Garnacho-Montero J, Montero C, Cano J, Palomino J, Valencia R, Álvarez R, Cordero E, Herrero M, Cisneros JM. Long-Term Impact of an Educational Antimicrobial Stewardship Program on Hospital-Acquired Candidemia and Multidrug-Resistant Bloodstream Infections: A Quasi-Experimental Study of Interrupted Time-Series Analysis. Clin Infect Dis. 2017;65:1992-9.

https://doi.org/10.1093/cid/cix692.

14.

Kontopantelis E, Doran T, Springate DA, Buchan I, Reeves D. Regression based quasi-experimental approach when randomisation is not an option: Interrupted time series analysis. BMJ. 2015;350:1-4. https://doi.org/10.1136/bmj.h2750.

15.

Almeida JP. in management and clinical decision support in a Hospital. Porto Biomed J. 2016;1:40-2. https://doi.org/10.1016/j.pbj.2015.12.001.

16.

WHO Collaborating Centre for Drug Statistics ATC/DDD index. 2013.

http://www.whocc.no/atc_ddd_index/.

17.

Tavares M, Carvalho AC, Almeida JP, Andrade P, São-Simão R, Soares P, Alves C, Pinto R, Fontanet A, Watier L. Implementation and impact of an audit and feedback antimicrobial stewardship intervention in the orthopaedics department of a tertiary-care hospital: a controlled interrupted time series study. Int J Antimicrob Agents. 2018;51:925-31. https://doi.org/10.1016/j.ijantimicag.2018.01.005.

18.

Adhikari S, Piza M, Taylor P, Deshpande K, Lam D, Konecny P. Sustained multimodal antimicrobial stewardship in an Australian tertiary intensive care unit from 2008-2015: an interrupted time-series analysis. Int J Antimicrob Agents. 2018;51:620-8. https://doi.org/10.1016/j.ijantimicag.2018.01.017. 19.

Knudsen JD, Andersen SE. (2014) A multidisciplinary intervention to reduce infections of ESBL- And AmpC-producing, Gram-negative bacteria at a university hospital. PLoS One 9:.

https://doi.org/10.1371/journal.pone.0086457.

Page 13/19 
20.

Andersen SE, Knudsen JD. A managed multidisciplinary programme on multi-resistant Klebsiella pneumoniae in a Danish university hospital. BMJ Qual Saf. 2013;22:907-15.

https://doi.org/10.1136/bmjqs-2012-001791.

21.

Norwegian Knowledge Centre for the Health Services. Effective Practice and Organisation of Care. Oslo: EPOC resources for review authors; 2015.

22.

Geissler A, Gerbeaux P, Granier I, Blanc P, Facon K, Durand-Gasselin J. Rational use of antibiotics in the intensive care unit: Impact on microbial resistance and costs. Intensive Care Med. 2003;29:49-54. https://doi.org/10.1007/s00134-002-1565-2.

\section{Tables}

Table 1 - General characteristics in Vascular Surgery ward and control group in pre-intervention and intervention periods.

\begin{tabular}{|c|c|c|c|c|c|c|}
\hline & \multicolumn{3}{|c|}{ Vascular Surgery } & \multicolumn{3}{|c|}{ General Surgery } \\
\hline & Pre-intervention & Intervention & p-value & Pre-intervention & Intervention & $\mathrm{p}$-value \\
\hline \multicolumn{7}{|l|}{ Per month: mean (sd) } \\
\hline Admissions (n) & $129(25)$ & $107(20)$ & $<0.001$ & $478(43)$ & $472(35)$ & 0.575 \\
\hline Elective admissions (\%) & $74.7(6.7)$ & $61.4(11.9)$ & $<0.001$ & $67.3(3.7)$ & $64.7(4.9)$ & 0.013 \\
\hline Men (\%) & $52.6(6.2)$ & $57.3(7.8)$ & 0.005 & $44.0(2.6)$ & $42.5(2.4)$ & 0.013 \\
\hline \multicolumn{7}{|l|}{ Age $(\%)$} \\
\hline$<40$ & $9.5(3.0)$ & $7.2(3.5)$ & 0.004 & $15.4(1.8)$ & $14.6(1.5)$ & 0.057 \\
\hline $40-64$ & $50.9(5.8)$ & $45.2(6.6)$ & $<0.001$ & $46.4(2.4)$ & $46.7(3.0)$ & 0.706 \\
\hline $65-74$ & $20.3(4.0)$ & $25.6(3.8)$ & $<0.001$ & $20.1(1.8)$ & $19.8(2.3)$ & 0.545 \\
\hline$>=75$ & $19.4(5.3)$ & $22.0(6.1)$ & 0.058 & $18.1(2.0)$ & $18.9(1.9)$ & 0.078 \\
\hline Average Length of Stay (days) & $7.7(1.5)$ & $9.0(1.4)$ & 0.001 & $5.1(0.5)$ & $5.7(0.4)$ & $<0.001$ \\
\hline 30-days Readmissions (\%) & $8.0(2.4)$ & $8.8(2.6)$ & 0.146 & $11.5(1.8)$ & $12.9(1.7)$ & 0.002 \\
\hline In-hospital death (\%) & $1.6(1.3)$ & $2.1(1.4)$ & 0.167 & $1.6(0.6)$ & $2.2(0.6)$ & $<0.001$ \\
\hline
\end{tabular}

Pre-intervention: January 2012 - March 2016; Intervention: April 2016-May 2018; sd: standard-deviation 
Table 2 - Interrupted time-series regression analysis of antibiotic consumption (carbapenems and all antibiotics) and antibiotic free-days in vascular and general surgery wards.

\begin{tabular}{|c|c|c|c|c|}
\hline & \multicolumn{2}{|c|}{ Vascular Surgery } & \multicolumn{2}{|l|}{ General Surgery } \\
\hline & Coefficient (95\%CI) & p-value & Coefficient (95\%CI) & p-value \\
\hline \multicolumn{5}{|l|}{ Carbapenem consumption (DDD/100 PD) } \\
\hline Baseline level) & $19.15(17.21 ; 21.08)^{*}$ & & $8.60(7.71 ; 9.50)^{*}$ & \\
\hline Pre-intervention slope) & $-0.12(-0.19 ;-0.06)^{*}$ & $<0.001$ & $-0.06(-0.09 ;-0.03)^{*}$ & $<0.001$ \\
\hline Level change (post intervention)) & $-9.94(-12.91 ;-6.97)^{*}$ & $<0.001$ & $-1.26(-2.63 ; 0.12)^{*}$ & 0.074 \\
\hline Slope post-intervention) & $0.14(-0.07 ; 0.35)^{* *}$ & 0.185 & $0.02(-0.08 ; 0.12)^{* *}$ & 0.651 \\
\hline \multicolumn{5}{|c|}{ Overall antibiotic consumption (DDD/100 PD) } \\
\hline Baseline level) & $55.91(51.90 ; 59.92)^{* *}$ & & $48.15(45.53 ; 50.79)^{* *}$ & \\
\hline Pre-intervention slope) & $0.09(-0.04 ; 0.22)^{* *}$ & 0.162 & $-0.12(-0.21 ;-0.04)^{* *}$ & 0.006 \\
\hline Level change (post intervention)) & $48.9(22.7 ; 75.16)^{* *}$ & $<0.001$ & $-23.55(-40.72 ;-6.37)^{* *}$ & 0.008 \\
\hline Slope post-intervention) & $-0.89(-1.31 ;-0.47)^{* *}$ & $<0.001$ & $0.46(0.19 ; 0.74)^{* *}$ & 0.001 \\
\hline \multicolumn{5}{|l|}{ Days without antibiotic (\%) } \\
\hline Baseline level) & $40.45(37.80 ; 43.11)^{*}$ & & $54.24(52.84 ; 55.63)^{* *}$ & \\
\hline Pre-intervention slope) & $0.09(0.01 ; 0.18)^{*}$ & 0.034 & $0.14(0.09 ; 0.19)^{* *}$ & $<0.001$ \\
\hline Level change (post intervention)) & $4.16(0.08 ; 8.25)^{*}$ & 0.046 & $6.85(-2.23 ; 15.94)^{* *}$ & 0.137 \\
\hline Slope post-intervention) & $0.12(-0.16 ; 0.41)^{* *}$ & 0.869 & $-0.16(-0.31 ;-0.02)^{* *}$ & 0.027 \\
\hline
\end{tabular}

* From model 1 (testing only level change) because slope post-intervention was not statistically significant in model 2;

** From model 2 (testing level and slope change)

\section{Figures}




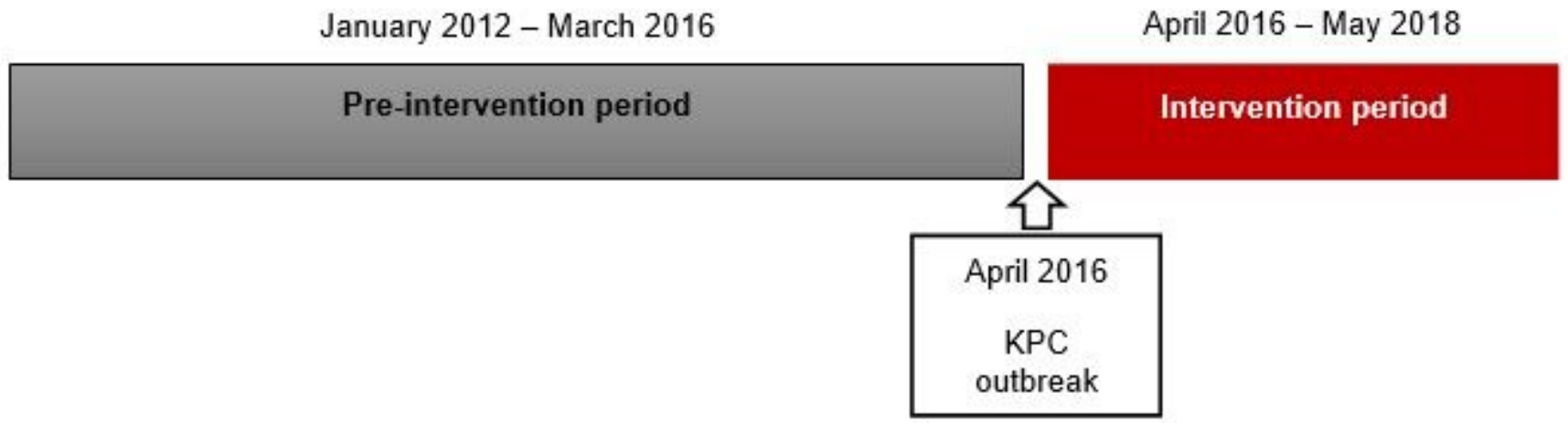

Figure 1

Schematic representation of the study periods. 


\section{Carbapenems Consumption Jan2012 - May2018}

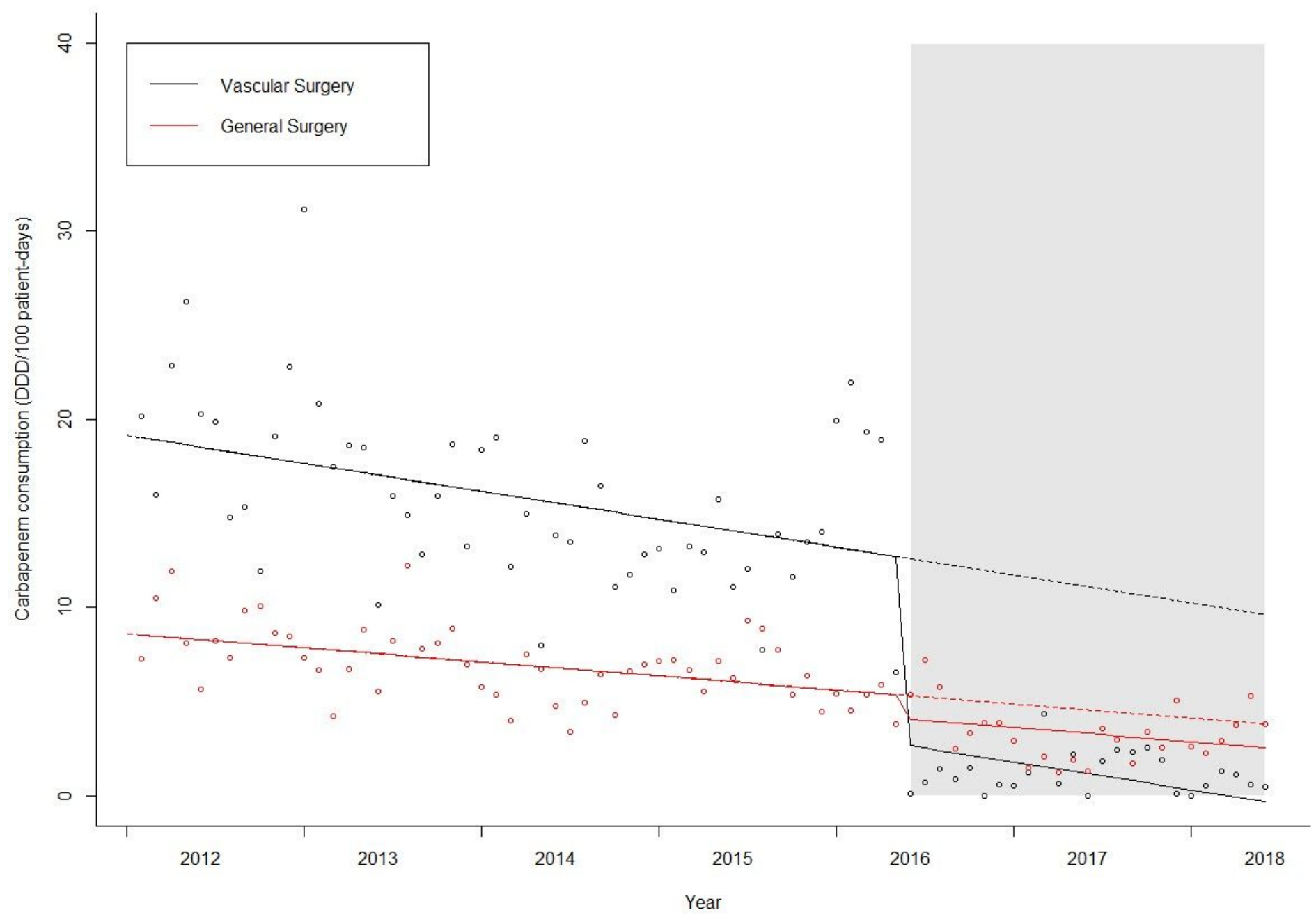

Figure 2

Interrupted time series for carbapenem consumption. Continuous line: predicted trend based on the level change model. Dashed line: counterfactual scenario. 
Antibiotic consumption Jan2012 - May2018

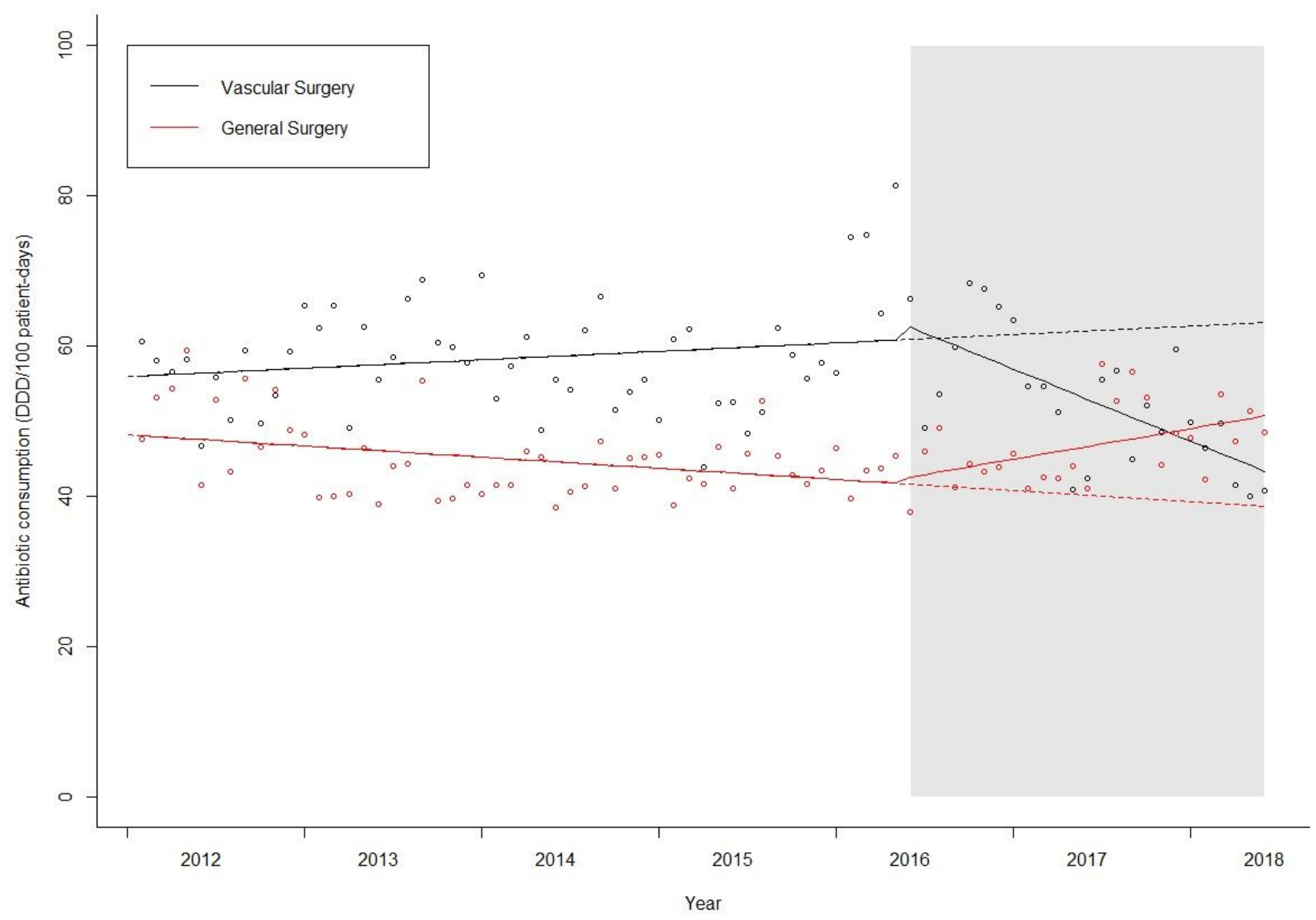

Figure 3

Interrupted time series for total antibiotic consumption. Continuous line: predicted trend based on the level and slope change model. Dashed line: counterfactual scenario. 
Days without antibiotic Jan2012 - May2018

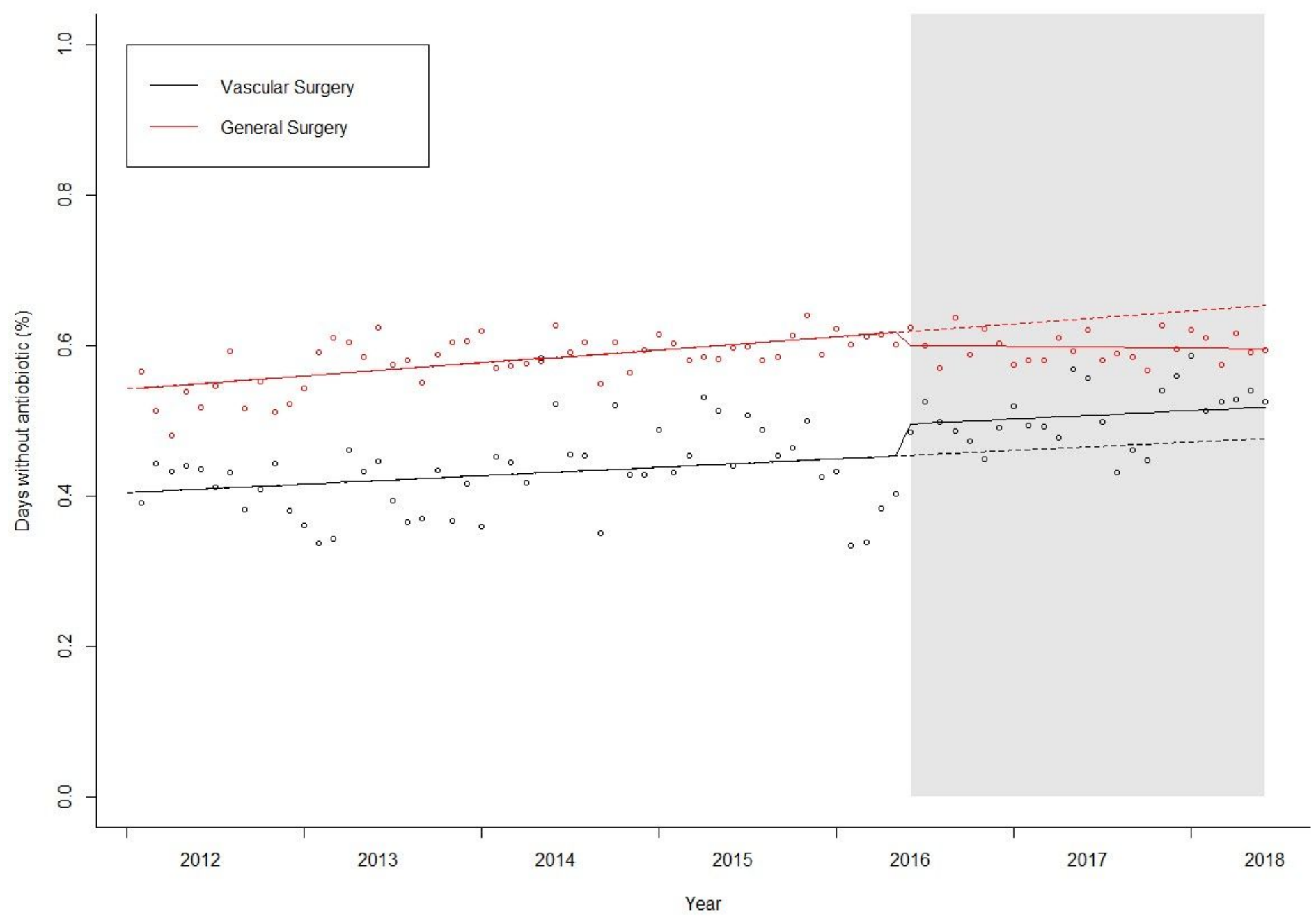

Figure 4

Interrupted time series for General Surgery department antibiotic-free days. Continuous line: predicted trend based on the level change model. Dashed line: counterfactual scenario.

\section{Supplementary Files}

This is a list of supplementary files associated with this preprint. Click to download.

- Supplementaryfilelnfection.docx 